\title{
DESIGUALDADES DE GÉNERO EN EL MERCADO DE TRABAJO ARGENTINO: SALARIO, EMPLEO E INFORMALIDAD LABORAL EN LAS MUJERES, 2004-2016
}

\section{GENDER INEQUALITIES IN THE ARGENTINIAN LABOUR MARKET: WAGES, EMPLOYMENT AND LABOUR INFORMALITY IN WOMEN, 2004-2016}

\author{
Débora Ascencio* \\ Eva Sacco** \\ Julia Strada ${ }^{* * *}$
}

\section{RESUMEN}

El presente artículo se propone explorar el vínculo entre las relaciones de género y el mercado de trabajo argentino entre 2004-2016, haciendo hincapié en caracterizar el perfil específico de la inserción laboral femenina durante el período mencionado, así como en identificar, en diálogo con la literatura especializada, las transformaciones operadas en una etapa trazada por cambios de gestión gubernamental y de políticas económicas. En cuanto a la metodología utilizada, se parte de técnicas cuantitativas a partir del análisis estadístico de los datos publicados por el Instituto Nacional de Estadística y Censos (INDEC). Por un lado, se utilizó la Encuesta Permanente de Hogares (EPH), para estudiar el desempeño de los principales indicadores económicos vinculados al salario, el empleo y la informalidad laboral $y$ por otro, se recurrió a la Encuesta sobre Trabajo No Remunerado y Uso del Tiempo, que permitió por primera vez en Argentina conocer datos oficiales en torno a la realización de tareas reproductivas y de cuidado, dimensión clave en los análisis económicos con perspectiva de género. Con las bases disponibles se realizó un ejercicio econométrico que cruza distintas variables socio-laborales.

PALABRAS CLAVE: ARGENTINA * MERCADO DE TRABAJO * ECONOMÍA DE GÉNERO * DESIGUALDAD * MUJER

\footnotetext{
* Centro de Innovación de los Trabajadores (CITRA) de ConicET, Universidad Metropolitana para la Educación y el Trabajo, Centro de Economía Política Argentina (CEPA), Argentina.

deborascencio@gmail.com

** Centro de Economía Política Argentina (CEPA), Universidad Nacional Arturo Jauretche (UNAJ) y Universidad Nacional de Avellaneda (UNDAV), Argentina. evasacco@gmail.com

*** Centro de Economía Política Argentina (CEPA), Área de Economía y Tecnología (AEYT)-FLACso Buenos Aires, Argentina. juliastrada@gmail.com
} 


\section{ABSTRACT}

The aim of this article is to analize the link between gender relations and the labor market in Argentina. The so-called feminist economy has examined these dilemmas in depth; however, there are still few studies that focus on the impact of recent public policies on the Argentinian labor market, with a gender perspective. In this sense, the main objective is to characterize the labor insertion of women, based on the main economic indicators linked to salary, employment and labor informality, in the recent period. As for the methodology, we resort to the statistical analysis of the data available in the Permanent Household Survey (EPH) and the Survey on the Use of Time published by the National Institute of Statistics and Censuses (INDEC). With the available databases, it was conducted an econometric exercise that crosses different socio-labor variables.

KEYWORDS: ARGENTINE * LABOUR MARKET * GENDER ECONOMICS * INEQUALITY* WOMEN

\section{INTRODUCCIÓN}

La economía feminista ha demostrado que en la dinámica del mercado de trabajo se manifiestan las desigualdades de género. En materia de salarios, empleo e informalidad laboral, las mujeres experimentan importantes desventajas que son pertinentes de analizar a la luz de nueva evidencia empírica que posibilite constatar en qué medida esas desigualdades persisten, se transforman $y$ adoptan un perfil específico. En Argentina, existen pocos trabajos ${ }^{1}$ que analicen de forma sistemática el perfil específico de inserción laboral femenina reciente.

En este sentido, la presente investigación describe la evolución de las principales variables del mercado de trabajo argentino con una mirada de género durante el período 2004-2016, posibilitando la construcción de un panorama riguroso de las formas de desigualdad en el mercado laboral en el período bajo análisis. Los principales hallazgos presentados resultan relevantes para una audiencia más amplia que la argentina por dos motivos. En primer lugar, en la medida que aportan evidencia empírica novedosa en diálogo con la teoría feminista, posibilita el análisis comparado a nivel regional. En segundo lugar, durante el período comprendido entre 2004 y 2016, en Argentina operaron numerosas transformaciones socioeconómicas y con

$1 \quad$ Algunos de los más relevantes son: Novick, M. et ál. (2008); Pérez, P. (2008); Halperin Weisburd, L. et ál. (2009); Brizuela, R. y Tumini, L. (2008), entre otros. relación al mercado laboral, tanto cuantitativa como cualitativamente. Como ejemplo destacable puede citarse la reducción significativa de la tasa de desempleo (pasó de $12,5 \%$ a $8,5 \%$ durante el período considerado), como resultado de una política activa en base al sostenimiento de los niveles de actividad y el empleo a partir de la extensión hacia las personas trabajadoras no registradas del derecho a las transferencias monetarias denominadas "asignaciones familiares" que hasta el momento solo percibían las personas trabajadoras registradas con hijos menores a cargo. También el reconocimiento jubilatorio a 4 millones de trabajadores (especialmente mujeres). En este contexto, resulta relevante como caso testigo, estudiar en qué medida estas mejoras que operaron durante el período, contribuyeron o no, a disminuir las desigualdades de género en el mercado laboral.

En cuanto al enfoque teórico, este trabajo se enmarca en un campo específico de estudio denominado "economía feminista"2, que

2 Los términos que definen al campo de la "economía feminista" son aún difusos por tratarse de una rama del pensamiento económico marginada académica y políticamente, aunque en proceso de expansión. Siguiendo a la autora española Amalia Pérez Orozco (2005), quien realiza una exhaustiva clasificación, se considera dentro del enfoque al conjunto de las corrientes que abordan cuestiones de género en la economía desde una perspectiva crítica con las desigualdades entre mujeres $y$ varones, en función del grado de ruptura con los paradigmas androcéntricos. 
comprende una serie de desarrollos teóricos preocupados por las desigualdades de género en el ámbito económico. Siguiendo la síntesis realizada por Corina Rodríguez Enríquez (2010), es posible señalar tres grandes ejes en los estudios que se enmarcan en dicho enfoque.

En primer lugar, la crítica epistemológica y metodológica a la economía neoclásica (Becker, 1973; 1974a y 1974b; Ferber y Nelson, 1993; Gardiner, 1997; Nelson, 1996 y Sen, 1990), en la medida que constituye una mirada androcéntrica de la economía, atribuyéndole al homo economicus características que considera universales, pero que sin embargo son propias de un ser humano varón, blanco, adulto, heterosexual y sano. Para la economía feminista, el accionar económico de los distintos actores se enfrenta a una serie de condicionantes de carácter social, cultural e histórico. Los mismos pueden obstaculizar o favorecer la capacidad para la toma de decisiones económicas por parte de los sujetos con un cierto nivel de autonomía. En la construcción de la autonomía de la acción, tiene incidencia el hecho de que las mujeres tengan a su cargo responsabilidades en el orden doméstico, así como también la realización de tareas de cuidados de menores y adultos mayores. Ello limita el acceso a recursos económicos, lo que deriva en un problema sistémico para el conjunto del género femenino.

En segundo lugar, la economía feminista recupera la dimensión reproductiva del sistema económico, donde la tensión entre producir mercancías y reproducir personas constituye la naturaleza del mercado laboral (Picchio, 2005). Esta división sexual del trabajo supone una primera $y$ fundamental desigualdad para las mujeres en su inserción laboral, en la medida que realizan la mayor parte del trabajo reproductivo no remunerado. Esto constituye a los hogares como instituciones de conflicto, ya que la oferta de trabajo remunerado se deduce de una negociación al interior de estos para la distribución del trabajo destinado a la reproducción de las personas (Picchio, 1999). Dentro de esta mirada, se destaca la contribución de la "economía del cuidado" que se propone, por un lado, visibilizar el rol sistémico del trabajo de cuidado en la economía y, por otro lado, dar cuenta de las implicancias que tiene para las mujeres la manera en que se organiza el cuidado.

El tercer eje está constituido por los análisis de las desigualdades al interior del mercado de trabajo y sus implicancias para la dinámica económica general. Existe una profusa literatura especializada que da cuenta de este fenómeno a nivel mundial y regional. Dilemas como el aumento de la participación de las mujeres en el mercado laboral sin que el mismo se traduzca en mayor autonomía, la existencia de una importante brecha salarial $y$ de ingresos entre varones y mujeres a pesar de estar más calificadas y tener más años de experiencia laboral, la presencia del llamado "techo de cristal" (glassceiling) que impide a las mujeres acceder en igualdad de condiciones a puestos jerárquicos, el fenómeno conocido como "piso pegajoso" (stickyfloor) que da cuenta de la situación de precariedad en las mujeres de los deciles de más bajos ingresos y menores perspectivas de movilidad social ascendente, son algunos de los ejes que recorren el campo.

La hipótesis fundamental que guía la investigación es que las desigualdades de género en el mercado de trabajo analizadas por la literatura feminista se constatan en el análisis de la evidencia empírica reciente para el caso argentino. Asimismo, la descripción del perfil específico de inserción laboral femenina permitirá corroborar que, si bien las inequidades económicas entre varones $y$ mujeres no son ajenas a la política económica implementada por las distintas gestiones de gobierno, sus causas responden también a elementos relativamente estructurales vinculados a estereotipos de género en torno a la división de las tareas reproductivas y de cuidado.

En el primer apartado, se realiza un análisis sobre la heterogeneidad en la dedicación al trabajo productivo y reproductivo en el caso de las mujeres, dado que este elemento constituye, según la bibliografía especializada (Esquivel, 2009; D'alessandro, 2016), el punto de partida de la desigualdad en el mercado de trabajo. Para ello, se analizan los datos disponibles a partir de la Encuesta sobre Trabajo No Remunerado y Uso del Tiempo que publicó el Instituto de Estadísticas y Censos (INDEC) en 2013, primer 
insumo estadístico disponible para medir la realización de tareas reproductivas y de cuidado en los hogares urbanos. En el segundo apartado, se realiza un análisis de la desigualdad salarial entre varones y mujeres a partir del cálculo de la brecha salarial en trabajadores registrados y un análisis de sus orígenes y condicionantes. En el tercer apartado, se analiza la evolución de la ocupación y la tasa de actividad femenina para interpretar la dinámica del empleo. En el cuarto apartado, se examinan las particularidades de la informalidad laboral. En el quinto apartado, se analiza la penalidad en las remuneraciones con carga de cuidado. El sexto y último apartado propone un modelo econométrico para los salarios, que aporta evidencia empírica en línea con las hipótesis planteadas y el análisis descriptivo realizado en los primeros cinco apartados.

\section{METODOLOGÍA}

Aquí se recurre a una estrategia metodológica cuantitativa, basada en el análisis estadístico de los datos disponibles en la Encuesta Permanente de Hogares (EPH) y la Encuesta sobre Trabajo No Remunerado y Uso del Tiempo de 2013, publicadas por el Instituto Nacional de Estadística y Censos (INDEC). En cuanto a la EPH, se complementa el análisis descriptivo con el análisis econométrico. Por un lado, se recuperan los principales indicadores económicos relacionados al empleo, salario e informalidad laboral desagregados por la variable de género, combinando el enfoque diacrónico y/o sincrónico en función del examen del impacto de las políticas públicas (diacrónico) y la caracterización del perfil específico de inserción laboral femenina actual (sincrónico). Así, en algunos temas se analiza el desempeño de ciertas variables en el largo plazo (por ejemplo, para evaluar la evolución de la brecha salarial de género) y en otros casos, se prioriza el enfoque sincrónico que da cuenta del impacto diferencial entre varones y mujeres de determinados fenómenos en la economía actual (por ejemplo, la tasa de desocupación según el género). Cabe indicar que la EPH recoge una muestra poblacional con proyección a 27 millones de habitantes de Argentina, comprendidos en los 31 aglomerados urbanos relevados. En efecto, queda excluida del análisis la población rural en Argentina.

Por otra parte, se recurre al análisis de los datos disponibles en la Encuesta sobre Trabajo No Remunerado y del Uso del Tiempo realizada en 2013, para dar cuenta de las características específicas de las tareas reproductivas al interior de los hogares. Esta constituye la primera y única fuente de información elaborada por el Instituto Nacional de Estadística y Censos de la República Argentina, realizada con el objetivo de captar información respecto de la participación y el tiempo destinado por las personas de 18 años y más a las tareas domésticas, al cuidado de miembros del hogar y al trabajo voluntario.

Resulta pertinente realizar una observación sobre los límites de las estadísticas disponibles para este tipo de trabajos. El INDEC utiliza la categoría sexo para la desagregación de los datos, la cual está determinada por la biología y donde existen solo dos opciones posibles: varón-mujer. $\mathrm{El}$ género ${ }^{3}$, en cambio, es una construcción social que no está determinada unívocamente por el sexo, sino que depende de otra serie de elementos que no pueden reducirse a factores biológicos. Esta situación afecta particularmente a identidades que no se inscriben en la lógica binaria, como las personas trans. En efecto, el concepto de género como categoría de análisis es una de las contribuciones teóricas más significativas del feminismo contemporáneo, cuyo desarrollo y problematización permitió romper con la idea del carácter natural del mismo (Gamba, 2007).

El recorrido propuesto hace eje en el concepto de brecha salarial y de ingresos, considerando como tal la diferencia porcentual entre los ingresos promedios de los varones respecto de las mujeres. En cada uno de los apartados se verifica a partir del análisis de diversos indicadores la existencia de una inserción laboral diferencial entre varones y mujeres. En el último apartado, por último, propone

\footnotetext{
3 Para mayores precisiones sobre el concepto de género como categoría analítica consultar Hernández, Y. (2006).
} 
un modelo econométrico basado en las ecuaciones de Mincer para los ingresos laborales de los activos (no solo en relación de dependencia), donde además de los controles típicos (experiencia, años de estudio, horas trabajadas) se incluyen como variables explicativas la rama de actividad, la presencia de menores en el hogar, si el trabajo es registrado, si es un puesto laboral en el sector público y si el puesto es directivo o de jefatura. También se incluyen las interacciones entre dichas variables y el género para poder dar cuenta de los efectos diferenciales. El modelo es estimado en dos momentos del tiempo: 2004 y 2016, con la finalidad de recuperar posibles cambios en los coeficientes del modelo durante el periodo considerado.

\section{LA HETEROGENEIDAD EN LA DEDICACIÓN AL TRABAJO PRODUCTIVO Y REPRODUCTIVO}

El punto de partida de las desigualdades de género en el mercado de trabajo es que las mujeres realizan la mayor parte del trabajo reproductivo no remunerado ${ }^{4}$, aspecto que condiciona el perfil específico de precariedad en la inserción laboral femenina. Las tareas domésticas y de cuidado, son llevadas a cabo mayoritariamente por mujeres en función de los estereotipos hegemónicos presentes en la sociedad que naturalizan la capacidad de las mujeres para "cuidar" y vinculados por el imaginario colectivo a ciertos atributos biológicos asociados a la maternidad. Sin embargo, "lejos de ser una capacidad natural, se trata de una construcción social sustentada por las relaciones patriarcales de género, que se sostiene en valoraciones culturales reproducidas por diversos mecanismos como la educación, los contenidos de las publicidades $y$ otras piezas de comunicación, la tradición, las prácticas domésticas cotidianas, las religiones, las instituciones" (Rodríguez, 2015, p. 9).

En la Encuesta sobre Trabajo No Remunerado y Uso del Tiempo del INDEC (2013), se identifica que las mujeres dedican en promedio más de tres horas diarias "extra" que los varones a realizar trabajo doméstico no remunerado ${ }^{5}$. Mientras que las mujeres dedican 3,4 horas diarias a los quehaceres domésticos, 1,9 horas diarias al cuidado de personas y 0,4 al apoyo escolar; los varones dedican solo 1,2 horas a quehaceres domésticos, 0,6 al cuidado de personas y $0,1 \mathrm{al}$ apoyo escolar. En el total, las mujeres consagran en promedio 5,7 horas diarias a la realización de trabajo doméstico no remunerado, mientras que los varones dedican solo 2 horas diarias (gráfico 1).
4 "El trabajo reproductivo hace referencia al trabajo destinado a satisfacer las necesidades de la familia. A pesar de constituir una dimensión necesaria para la reproducción de la sociedad, su desarrollo ha quedado históricamente circunscrito al marco privado, primordialmente a la esfera doméstica, razón por la que también se define como «trabajo doméstico» o «familiar»*. E1 escenario fundamental para su desarrollo es el hogar, pero su espacio físico y simbólico no se reduce exclusivamente a este ámbito, e incluye actividades de gestión, relación, mantenimiento, cuidado, etcétera" (Larrañaga, Arregui y Arpal, 2004).

5 Esto conforma una suerte de "doble jornada laboral" para las mujeres que además se desempeñan en el trabajo productivo y remunerado dado que en total son 6 horas diarias dedicadas por las mujeres en promedio a las tareas domésticas. 

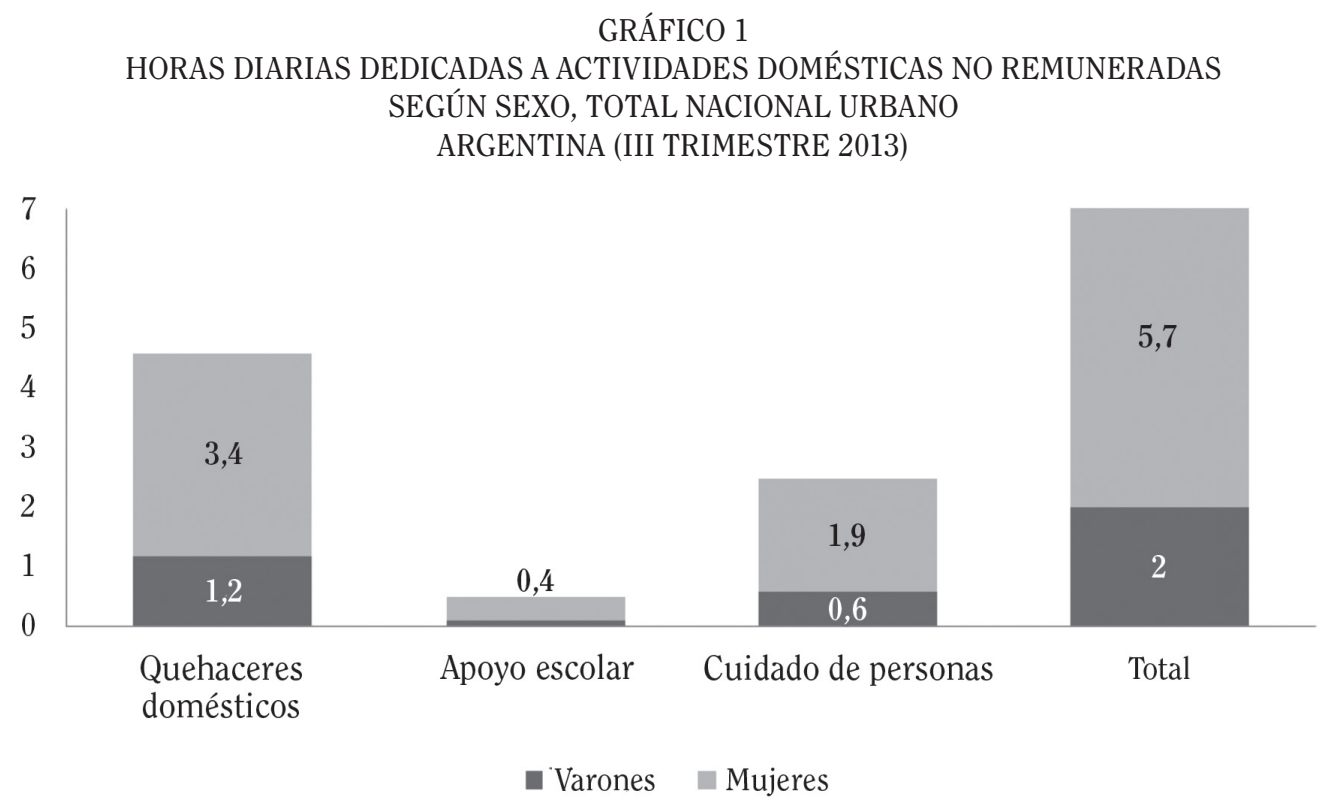

Fuente: Elaboración propia con base en la Encuesta sobre Trabajo No Remunerado y Uso del tiempo, INDEC (2013).

Independientemente de que las mujeres se hayan incorporado de manera masiva al mercado de trabajo durante los últimos años ${ }^{6}$, los varones no asumieron - de manera concomitante a dicha incorporación femenina a la esfera de la producción- más tareas reproductivas en los hogares. Aún en los casos en los cuales las mujeres trabajan y son jefas de hogar, realizan más tareas reproductivas que los varones. Mientras que los varones jefes de hogar dedican 3,6 horas diarias en promedio a este tipo actividades, las mujeres jefas de hogar lo hacen en 5,7 horas. La diferencia se incrementa para el caso de los cónyuges de la persona jefa de hogar. Mientras que los varones que conviven con el sostén del hogar dedican 3,4 horas diarias a las tareas reproductivas, las mujeres lo hacen en 7,6 horas (tabla 1). Resulta particularmente llamativo que prácticamente no se produce variación alguna entre el tiempo destinado a las tareas domésticas por los varones jefes o cónyuges del hogar, incluso disminuyendo un punto para este último caso. Es válido suponer que la disponibilidad horaria del varón que convive con la jefa del hogar es mayor para la realización de las tareas domésticas. Sin embargo, que la mayor carga reproductiva siga estando del lado de las mujeres, resulta un indicador del componente de género en este tipo de labores.

6 A partir de la década de los 60 , la incorporación de las mujeres al mercado de trabajo se masifica. Entre las causas fundamentales de dicho fenómeno se destacan el acceso a mayores niveles educativos y las transformaciones culturales que influyeron en el cambio de las pautas reproductivas y de fecundidad. Este proceso avanzó de manera gradual hasta los 80 , acelerándose durante los 90 , asociado al aumento del desempleo y al deterioro de los salarios reales de los jefes varones (Barrancos, 2007; Contartese y Maceira, 2006; Cerrutti, 2000). 
TABLA 1

HORAS DIARIAS PROMEDIO DEDICADAS AL TRABAJO DOMÉSTICO NO REMUNERADO SEGÚN SEXO Y RELACIÓN CON EL JEFE DEL HOGAR

ARGENTINA (III TRIMESTRE 2013)

\begin{tabular}{ccc}
\hline & PERSONA JEFA DE HOGAR & CÓNYUGE DE LA PERSONA JEFA DE HOGAR \\
\hline Varón & 3,6 & 3,4 \\
Mujer & 5,3 & 7,6 \\
\hline Diferencia & 1,7 & 4,2 \\
\hline
\end{tabular}

Fuente: Elaboración propia con base en la Encuesta sobre Trabajo No Remunerado y Uso del tiempo, INDEc (2013).

TABLA 2

HORAS PROMEDIO DIARIAS DEDICADAS AL TRABAJO REPRODUCTIVO

SEGÚN NIVEL EDUCATIVO

ARGENTINA (III TRIMESTRE 2013)

\begin{tabular}{lccc}
\hline & $\begin{array}{c}\text { HASTA PRIMARIA } \\
\text { COMPLETA }\end{array}$ & $\begin{array}{c}\text { SECUNDARIA COMPLETA O } \\
\text { INCOMPLETA }\end{array}$ & $\begin{array}{c}\text { SUPERIOR UNIVERSITARIA } \\
\text { COMPLETA O INCOMPLETA }\end{array}$ \\
\hline Varón & 3,3 & 3,5 & 3,3 \\
Mujer & 6,1 & 7,2 & 5,5 \\
\hline Diferencia & 2,8 & 3,7 & 2,2 \\
\hline
\end{tabular}

Fuente: $\quad$ Elaboración propia con base en la Encuesta sobre Trabajo No Remunerado y Uso del tiempo, INDEC (2013).

Cuando se controla la distribución de género en el trabajo reproductivo según nivel educativo, se observa que la brecha entre varones $y$ mujeres persiste, oscilando entre dos $y$ tres horas diarias más dedicadas por las mujeres a las tareas de este tipo. Para el caso de la población con secundaria completa e incompleta, las mujeres dedican 3,7 horas extra en promedio; para el caso de la población con primaria completa, las mujeres dedican 2,8 horas extra; mientras que para el caso de la población superior universitaria completa o incompleta, las mujeres dedican 2,2 horas extra con respecto a los varones en la realización de tareas domésticas (tabla 2).

La primera consecuencia de la desigualdad en la dedicación horaria a las tareas domésticas $y$ de cuidado, es que las mujeres disponen de menos horas diarias para dedicar al trabajo productivo y remunerado. Según el INDEC (2013), mientras que los varones dedican en promedio 35 horas semanales en tareas por las cuales perciben una remuneración, las mujeres dedican solo 17,6 horas, afectando los ingresos percibidos ${ }^{7}$. Pero además, esta forma de desigualdad condiciona el perfil específico de inserción laboral que portan, caracterizado por mayores niveles de precariedad que los varones. A continuación, se analizan cuatro aspectos vinculados al perfil de mayor precariedad: desigualdad en los ingresos, desempleo, informalidad laboral $y$ penalidad en remuneraciones con carga de cuidado.

\section{DESIGUALDAD SALARIAL ENTRE VARONES Y MUJERES: UN ANÁLISIS DE LA BRECHA}

En este apartado se efectúa una descripción detallada de la desigualdad salarial y de

$7 \quad$ Este aspecto forma parte de los condicionantes de la brecha de ingresos percibidos entre varones $y$ mujeres que se analiza en apartados posteriores. 
ingresos entre varones y mujeres, tanto desde el punto de vista sincrónico como diacrónico, para dar cuenta de la magnitud y distribución en el largo plazo del fenómeno. En los apartados posteriores, se realiza un análisis de tres de los principales condicionantes de dicha desigualdad: desocupación, informalidad laboral y penalidad en remuneraciones con carga de cuidado.

GRÁFICO 2

SALARIO PROMEDIO DE TRABAJADORES Y TRABAJADORAS REGISTRADAS EN PESOS ARGENTINOS ARGENTINA (II TRIMESTRE 2004-II TRIMESTRE 2016)

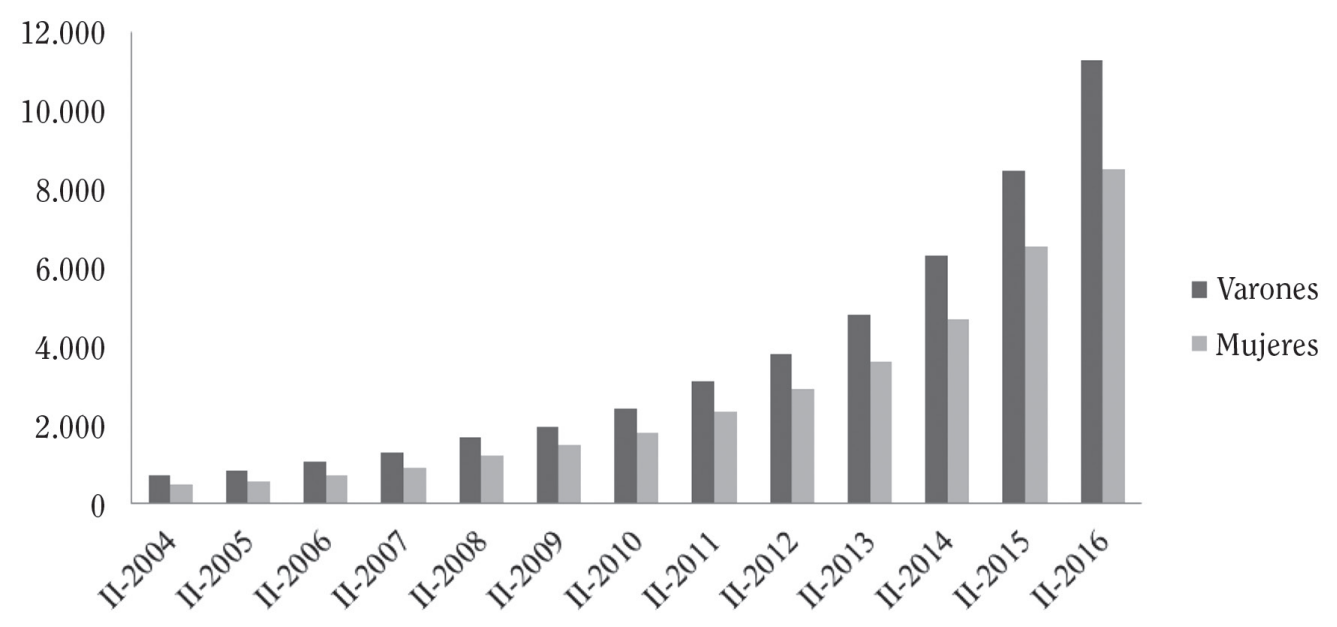

Fuente: Elaboración propia con base en EPH-INDEc, 2004 y 2016.

La desigualdad salarial de género constituye una de las problemáticas económicas más analizadas por la literatura feminista ${ }^{8}$ $y$ alude a que las mujeres perciben salarios más bajos que los varones (gráfico 2). Metodológicamente, una de las formas más difundidas para medir el fenómeno es a partir del cálculo del porcentaje salarial adicional que tiene el salario promedio de los varones por sobre el salario promedio de las mujeres. El mismo se ubica en 25\% para el II trimestre de 2016, en el caso de los trabajadores $y$ trabajadoras registradas de Argentina. Es decir, que las mujeres perciben en promedio salarios registrados un $25 \%$ más bajos que los varones (gráfico 3).

8 Algunas referencias relevantes sobre la temática son: Contreras y Gallegos (2007), García de Fanelli (1989), Recio (2012), Simón (2009) y Meza (2005). 


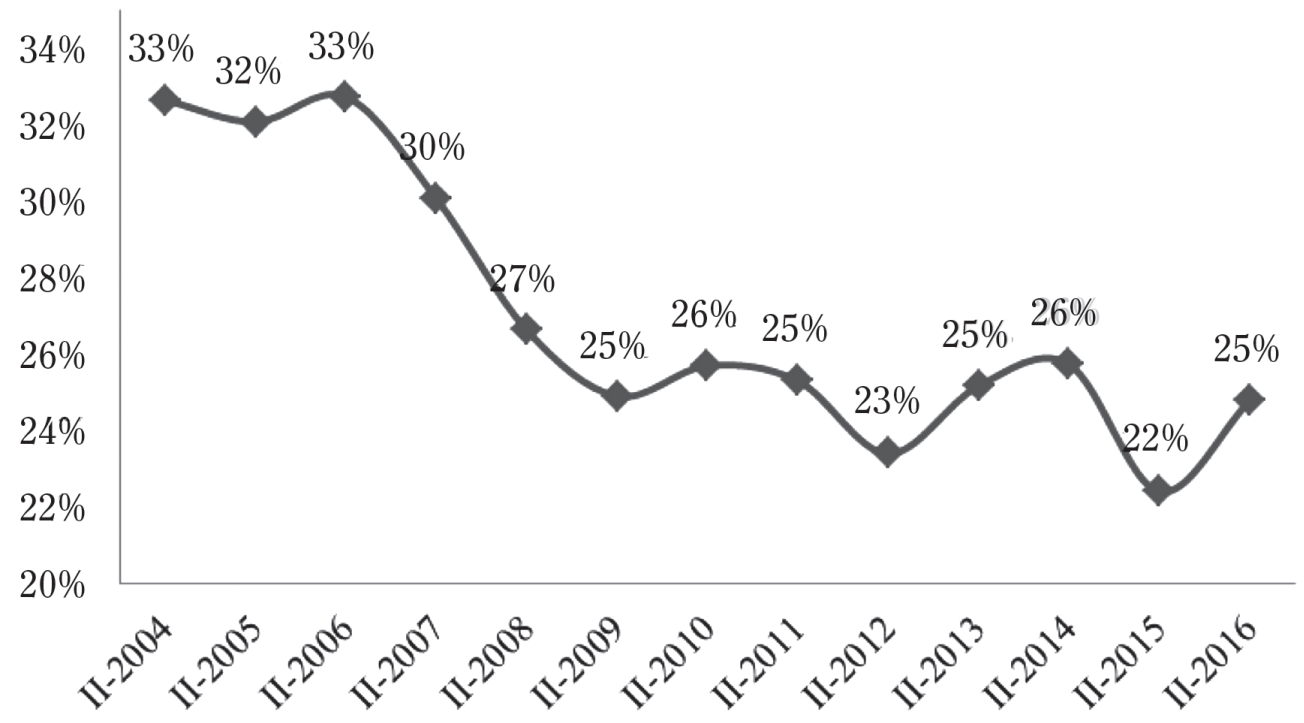

Fuente: $\quad$ Elaboración propia con base en EPH-INDEC, 2004 y 2016.

La evolución de la brecha salarial de género en el largo plazo permite observar que se ha reducido en 8 puntos porcentuales (con oscilaciones) entre 2007 y 2015, manifestando un leve repunte en 2016. Esta situación acompaña la dinámica general del mercado laboral durante las gestiones gubernamentales Kirchneristas (2003-2015), donde indicadores como salario real, empleo y reducción de la informalidad laboral manifestaron un importante dinamismo ${ }^{9}$.

$9 \quad$ Distintos autores académicos resaltan las transformaciones que se han experimentado en la posconvertibilidad en Argentina, a partir de variables macroeconómicas que dan cuenta del incremento en los puestos de trabajo formales, en el salario nominal y real, $y$ de la recuperación de posiciones en la participación de los asalariados en el ingreso (Santarcángelo, 2011; Beccaria, Maurizio y Vázquez, 2015; Beccaria y Maurizio, 2008; Basualdo, 2012, CIFRA-CTA, 2011 y Kulfas, 2016), al mismo tiempo que se observa una reestructuración
Ahora bien, tal como se anticipa en la introducción, la hipótesis de este es trabajo, en línea con la literatura especializada, es que el origen de la brecha salarial responde también a factores relativamente estructurales vinculados a la desigual distribución en las tareas reproductivas de cuidado que condicionan las posibilidades de inserción laboral femenina.

Una señal de que la percepción de salarios más bajos responde a una problemática de género, $y$ no a que la diferencia salarial entre varones $y$ mujeres se debe a que los primeros presentan mejor calificación para desempeñarse en puestos mejor remunerados, es que cuando se consideran tanto los años de educación y de experiencia laboral, se observa que las mujeres están en promedio más calificadas (tabla 3 ).

de un marco institucional $y$ regulatorio de protección a la clase trabajadora, a partir de la recuperación de la negociación paritaria. 
TABLA 3

AÑOS DE EDUCACIÓN Y EXPERIENCIA LABORAL PROMEDIO SEGÚN SEXO ARGENTINA (II TRIMESTRE 2016)

\begin{tabular}{ccc} 
& AÑOS DE EDUCACIÓN PROMEDIO & AÑOS DE EXPERIENCIA LABORAL PROMEDIO \\
\hline Mujeres & 9,0 & 20,2 \\
Varones & 8,6 & 18,3 \\
\hline
\end{tabular}

Fuente: Elaboración propia con base en EPH-INDEC, 2016.

En cuanto a los años de educación, las mujeres detentan en promedio 9 años, mientras que los varones acreditan 8,6. La misma tendencia se mantiene cuando se consideran los años de experiencia laboral: mientras que las mujeres en promedio cuentan con 20,2 años de experiencia laboral, los varones lo hacen solo con 18,3.

Así, la existencia de una brecha salarial del $25 \%$ entre varones y mujeres, no responde a que los varones cuenten eventualmente con "mayores capacidades" que las mujeres para el ejercicio de puestos mejor remunerados. Analizar la distribución en los años de educación $y$ experiencia laboral promedio, es consistente con la hipótesis de que la desigualdad salarial entre varones $y$ mujeres no responde a una cuestión de mérito. El análisis que sigue a continuación pretende aportar evidencia acerca de desigualdades de género estructurales que determinan la existencia de una brecha salarial.

En este sentido, hombres y mujeres se distribuyen de forma desigual entre los distintos deciles de ingreso. Las mujeres se encuentran sobre representadas en los deciles de más bajos ingresos, siendo mayoría en los deciles 1 y 2 ; mientras que los varones se encuentran sobre representados en los deciles de más altos ingresos, siendo mayoría en los deciles 9 y 10 . Si tomamos el IV trimestre de 2016, se observa que las mujeres representan el $14 \%$ y $13 \%$ respectivamente en el decil de salarios 1 y 2; mientras que los varones representan solo el 3\% y $4 \%$ en esos deciles. Por otra parte, considerando los deciles 9 y 10, los varones representan el 12\% y $13 \%$, mientras que las mujeres representan solo el $9 \%$ y $7 \%$ respectivamente (tabla 4). Ahora bien, considerando que la población de mujeres se ubica mayoritariamente en los deciles de más bajos ingresos, podría pensarse que el diferencial de ingresos entre varones $y$ mujeres no se debe a una discriminación de género, sino a una cuestión de mérito. Sin embargo, cuando se considera la brecha salarial de género según el máximo nivel educativo alcanzado y el nivel de calificación, se observa que la misma persiste en todos los niveles de ingreso (gráfico 4).

TABLA 4

DISTRIBUCIÓN DEL SALARIO POR DECILES SEGÚN SEXO EN PORCENTAJE ARGENTINA (2016)

\begin{tabular}{ccc}
\hline DECILES DE SALARIOS & HOMBRES & MUJERES \\
\hline 1 & $3 \%$ & $14 \%$ \\
2 & $6 \%$ & $13 \%$ \\
4 & $10 \%$ & $11 \%$ \\
5 & $11 \%$ & $10 \%$ \\
6 & $11 \%$ & $9 \%$ \\
7 & $13 \%$ & $10 \%$ \\
8 & $13 \%$ & $8 \%$ \\
9 & $12 \%$ & $9 \%$ \\
10 & $13 \%$ & $7 \%$ \\
\hline
\end{tabular}

Fuente: $\quad$ Elaboración propia con base en EPH-INDEC, 2016. 

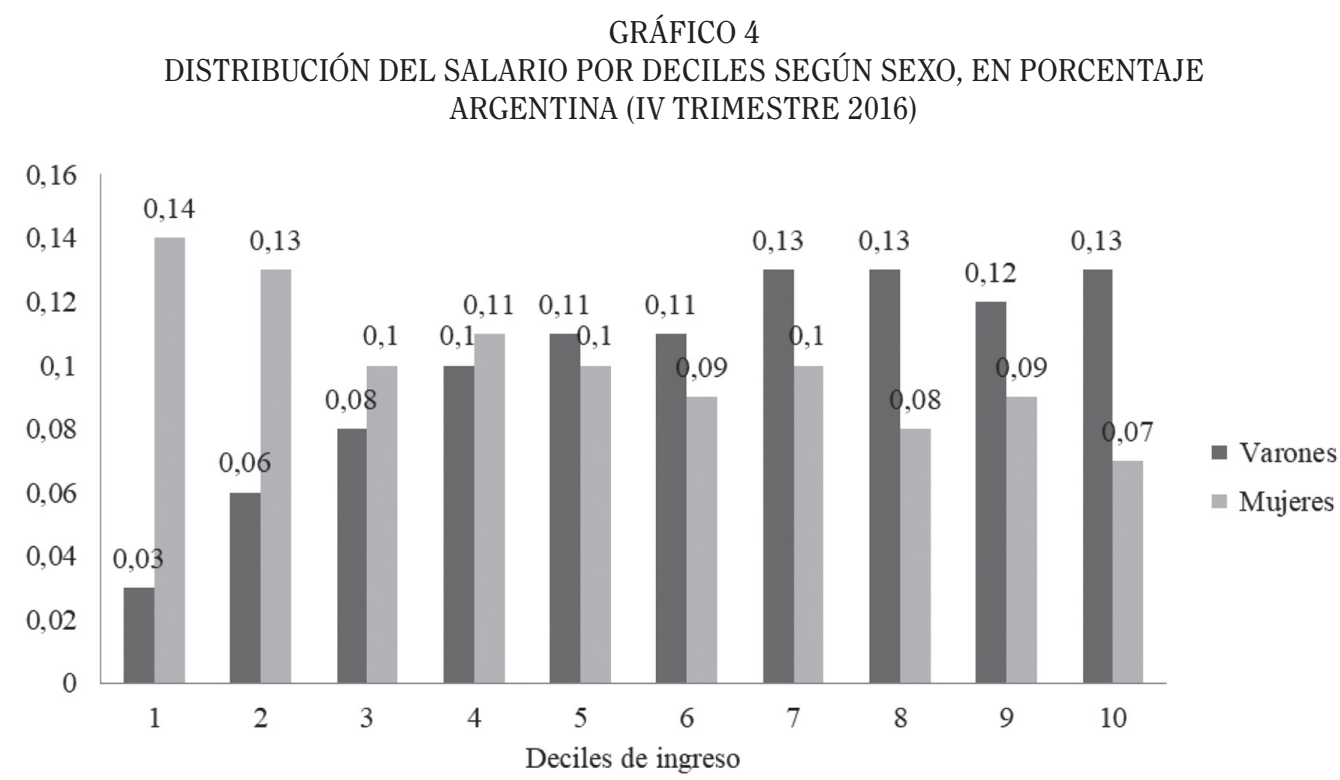

Fuente: Elaboración propia con base en EPH-INDEC, 2016.

En cuanto a la evolución de la brecha salarial según nivel de calificación, desde el año 2004 hasta el 2016 es posible observar que se manifiesta más fuertemente en la calificación profesional y la calificación baja. Para el caso de la calificación profesional, se observa una subida importante desde 2004 hasta 2007, aunque desde 2008 hasta 2015 comienza a bajar de forma sostenida y en 2016 vuelve a recuperar la tendencia alcista. Para el caso del nivel de calificación bajo, se mantiene en niveles altos durante todo el período bajo consideración. A pesar de las oscilaciones en uno y otro caso, la brecha de género para la calificación profesional y baja se mantiene muy por encima de los niveles de calificación técnico y medio. Inclusive, la brecha de género en las calificaciones técnica y media manifestó, en algunos años, una evolución negativa (es decir, que los salarios de las mujeres superaron en promedio el de los varones) (gráfico 5). 
GRÁFICO 5

BRECHA SALARIAL (SALARIO HORARIO) DE GÉNERO

SEGÚN NIVEL DE CALIFICACIÓN EN PORCENTAJE

ARGENTINA (II TRIMESTRE 2004-II TRIMESTRE 2016)

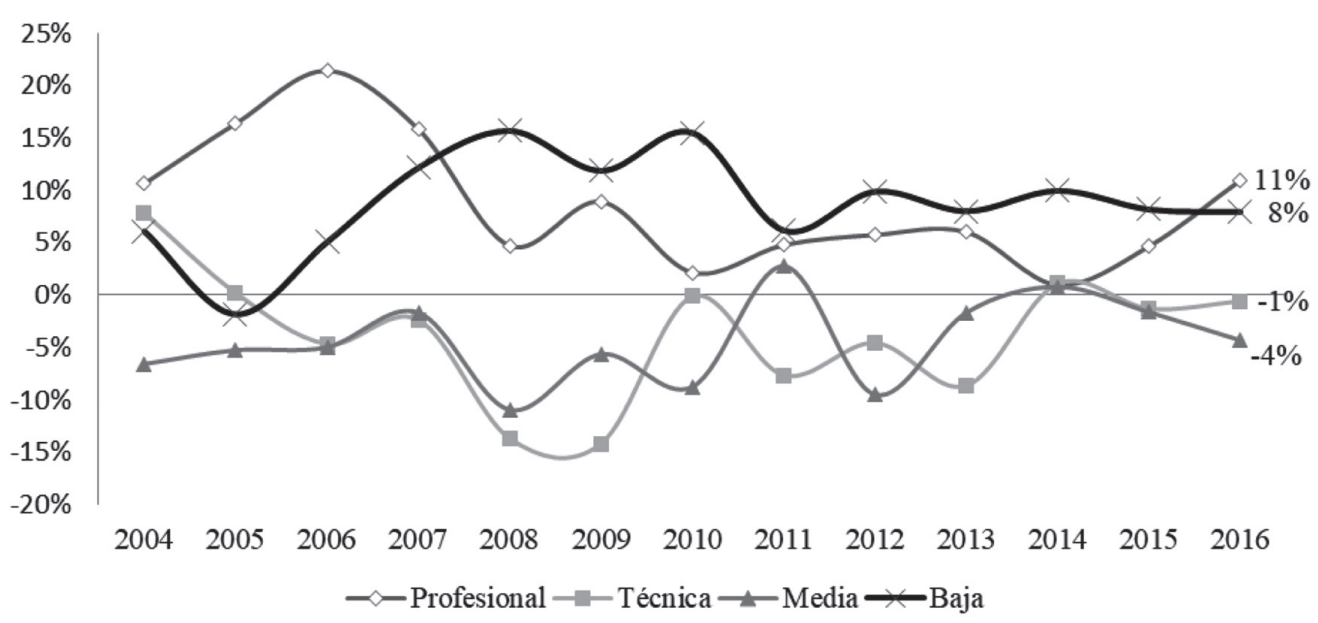

Fuente: $\quad$ Elaboración propia con base en EPH-INDEC, 2004 y 2016 .

El hecho de que las mujeres con calificación profesional presenten una de las brechas salariales más importantes, es un fenómeno ampliamente analizado desde la literatura feminista, atribuido a la existencia del "techo de cristal" (Sarrió, Barberá, Ramos y Candela, 2002). Las mujeres encuentran numerosas dificultades para acceder a puestos jerárquicos (y por lo tanto de mayor remuneración), tanto en el ámbito público como privado, a pesar de estar igual o más calificadas que los varones para ejercerlos. Por otra parte, que las mujeres de calificación baja también presenten los niveles más altos de brecha salarial, se explica en parte porque las mismas suelen desempeñarse en tareas feminizadas que se ubican entre las peor remuneradas (como el trabajo doméstico) $y$ que poseen una doble penalidad: por ser trabajos precarios $y$ por estar asociados a tareas del cuidado (Arriagada, 1997; Esquivel, 2011a, 2011b y 2012).

Cuando se considera la brecha salarial de género según el máximo nivel educativo alcanzado, se observa que en todos los casos es positiva (gráfico 6). Las brechas más importantes se dan en primaria completa $y$ secundaria completa. Para el caso de terciario y/o universitario completo, si bien la brecha es la más baja, persiste. 

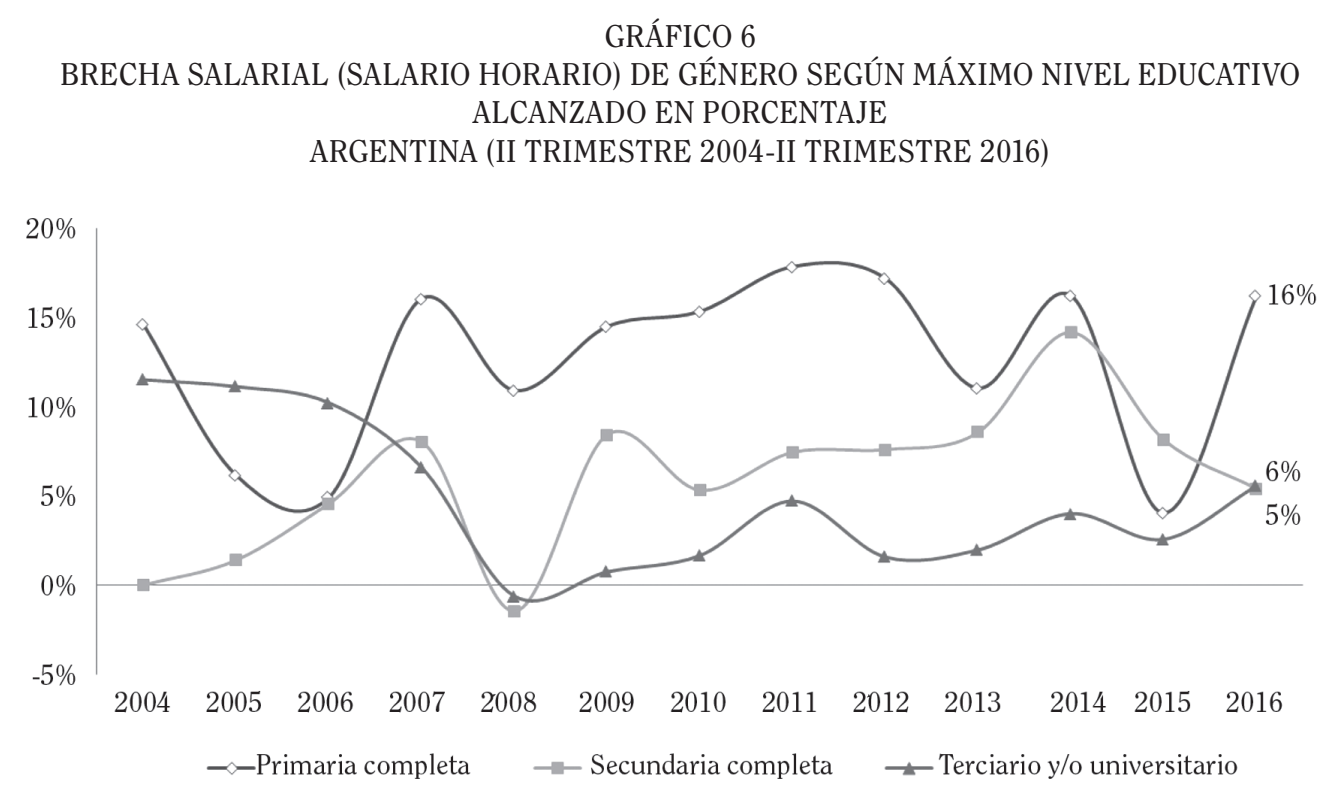

Fuente: $\quad$ Elaboración propia con base en EPH-INDEc, 2004 y 2016.

En síntesis, la brecha salarial de género para las trabajadoras registradas es acompañada por la distribución desigual en los deciles de ingresos, dado que las mujeres son mayoría en los deciles de más bajos salarios y a la inversa, son minoría en los deciles más altos. En el IV trimestre de 2016 la brecha se ubicó en el 25\%. Ahora bien, cuando se observa la evolución en el largo plazo se constata que la misma tuvo oscilaciones coincidentes con la evolución de la actividad económica $y$ de los indicadores del mercado de trabajo en general. Sin embargo, la brecha no se sostuvo cerca del $20 \%$, aspecto que da cuenta de una raíz estructural que requiere analizar sus causas en profundidad. Se corrobora que la brecha salarial de género se da en todos los niveles educativos, erosionando el mito del "mérito" en la formación profesional y por el contrario, es consistente con la hipótesis de desigualdades estructurales respecto de las características diferenciales en la inserción laboral de varones y mujeres. Por último, se constata que la brecha salarial de género se manifiesta en las puntas, con los niveles de calificación alto y bajo, dando cuenta de la presencia de los fenómenos analizados por la teoría feminista como "techos de cristal" $y$ "pisos pegajosos".

\section{TASA DE ACTIVIDAD FEMENINA Y HORAS OCUPADAS}

Durante el año 2016, periodo de empeoramiento del salario real y caída del nivel de empleo en Argentina, las mujeres disminuyeron la cantidad de horas trabajadas en un promedio de 2 horas (comparando los segundos trimestres para evitar efectos de estacionalidad). Los varones (aun trabajando más cantidad de horas) no disminuyeron las horas de su participación laboral (tabla 5). En épocas de expansión económica, la caída de las horas trabajadas es consistente con la retirada de las mujeres del mercado laboral para realizar otro tipo de tareas (generalmente reproductivas dentro del hogar), aspecto que correlaciona con una disminución en la tasa de actividad femenina (Novick, Rojo y Castillo, 2008). Sin embargo, la tasa de actividad femenina se incrementó 2 puntos porcentuales pasando de $35,94 \%$ en el segundo 
trimestre de 2015 a $37,94 \%$ en el segundo trimestre de 2016 (tabla 6). Si tomamos el total de la población cubierta por la Encuesta
Permanente de Hogares, se trata de aproximadamente 200000 mujeres adicionales que se volcaron al mercado laboral en 2016.

TABLA 5

HORAS SEMANALES TRABAJADAS EN LA OCUPACIÓN PRINCIPAL, SEGÚN SEXO ARGENTINA (2015-2016)

\begin{tabular}{cccccc}
\hline & II T 2015 & II T 2016 & III T 2016 & IV T 2016 & $\begin{array}{c}\text { VARIACIÓN } \\
\text { (II T 2016/ II T 2015) }\end{array}$ \\
\hline Varones & 46 & 46 & 45 & 45 & $0 \%$ \\
Mujeres & 40 & 38 & 39 & 37 & $-5 \%$ \\
\hline
\end{tabular}

Fuente: Elaboración propia con base en EPH, 2015-2016.

TABLA 6

EVOLUCIÓN DE LA TASA DE ACTIVIDAD FEMENINA EN PORCENTAJE ARGENTINA (2015-2016)

\begin{tabular}{|c|c|c|c|c|c|}
\hline & II T 2015 & II T 2016 & III T 2016 & IV T 2016 & $\begin{array}{l}\text { VARIACIÓN (IIT } \\
2016 \text { / IIT 2015) }\end{array}$ \\
\hline Varones activos & $53,39 \%$ & $54,58 \%$ & $54,48 \%$ & $53,84 \%$ & $2 \%$ \\
\hline Mujeres activas & $35,94 \%$ & $37,94 \%$ & $38,24 \%$ & $37,49 \%$ & $6 \%$ \\
\hline
\end{tabular}

Fuente: $\quad$ Elaboración propia con base en EPH, 2015-2016.

En el mismo sentido, cuando se analiza la ocupación demandante femenina, se observa que la caída en la cantidad de horas trabajadas por las mujeres en promedio coexiste con el incremento en la ocupación demandante femenina. Mientras que en el caso de los varones, el incremento en la ocupación demandante es menor. Así, en contextos de caída del empleo como el que tuvo lugar en el año 2016 (la caída fue de $0,7 \%$, totalizando 43603 empleos registrados menos, según el Ministerio de Trabajo), las mujeres son las más afectadas. La existencia de evoluciones contrarias entre las horas trabajadas por las mujeres y la tasa de ocupación demandante femenina, si bien es un dato agregado, resulta contradictorio con la lectura de la existencia de una brecha salarial que es consecuencia de un arreglo al interior de los hogares, $y$ son las mismas mujeres las que deciden dedicarse menos intensivamente al trabajo productivo (tabla 7 ).

Por último, vale aclarar que la existencia de una diferencia persistente en las horas trabajadas por varones $y$ mujeres puede tomarse como un factor explicativo de la brecha salarial. Sin embargo, como se verá en las secciones subsiguientes existen otros factores que complementan la menor dedicación al trabajo remunerado de las mujeres y que está en relación con la inserción laboral de ellas. 
TABLA 7

TASA DE OCUPACIÓN DEMANDANTE

ARGENTINA (2015-2016)

\begin{tabular}{lccccc}
\hline & II T 2015 & II T 2016 & III T 2016 & IV T 2016 & $\begin{array}{c}\text { INCREMENT } \\
\text { (IIT 2016/ } \\
\text { IIT2015) }\end{array}$ \\
\hline Ocupado demandante varón & $15,63 \%$ & $19,53 \%$ & $17,92 \%$ & $17,82 \%$ & $14 \%$ \\
Ocupado demandante mujer & $13,21 \%$ & $17,29 \%$ & $15,07 \%$ & $15,34 \%$ & $16 \%$ \\
\hline
\end{tabular}

Fuente: Elaboración propia en base en EPH-INDEc, 2015-2016.

\section{LA INFORMALIDAD LABORAL EN LAS MUJERES EN ARGENTINA}

Otra fuente importante de vulnerabilidad en la inserción laboral femenina es el mayor nivel de informalidad o de empleo no registrado que presentan. Para el IV trimestre de 2016, el $29 \%$ de los varones trabaja de manera informal, mientras que para el caso de las mujeres el porcentaje asciende a 35\%. De acuerdo con la medición de EPH, a nivel operativo, la definición de no registración o informalidad laboral significa que no tienen aportes patronales por su trabajo ni acceden a una obra social cubierta también por las contribuciones del empleador y los aportes personales de un salario registrado.

\section{GRÁFICO 7}

ÍNDICE DE INFORMALIDAD LABORAL PROMEDIO EN VARONES Y MUJERES EN PORCENTAJE ARGENTINA (II TRIMESTRE 2004-II TRIMESTRE DE 2016)

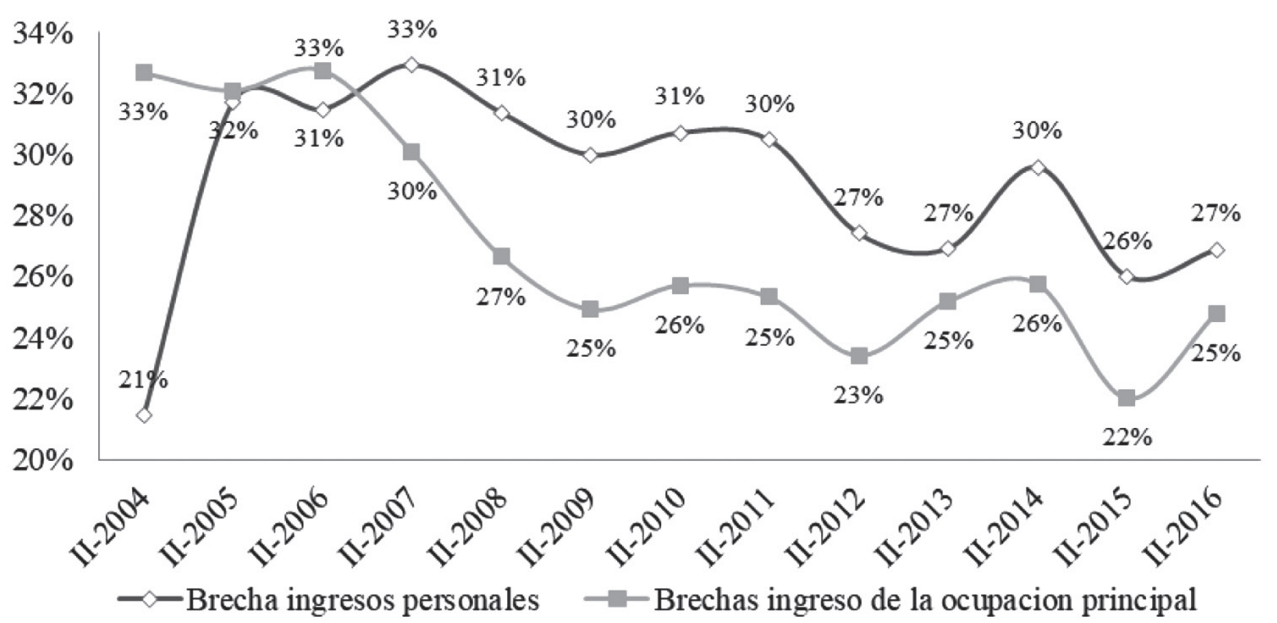

Fuente: $\quad$ Elaboración propia con base en EPH-INDEC, 2016. 
Cuando se analiza la evolución de la informalidad laboral durante el periodo en estudio, se observa que la brecha entre varones y mujeres se redujo durante el período 2004-2015 (gráfico 7). Para el II trimestre de 2004, el 40\% de los varones trabajaba de manera informal, la mujeres lo hacían en un 51\% (11 puntos porcentuales de diferencia). Durante el II trimestre de 2016, los varones se veían afectados por la informalidad laboral en un $29 \%$, mientras que las mujeres lo hacían en un 35\% (gráfico 8).

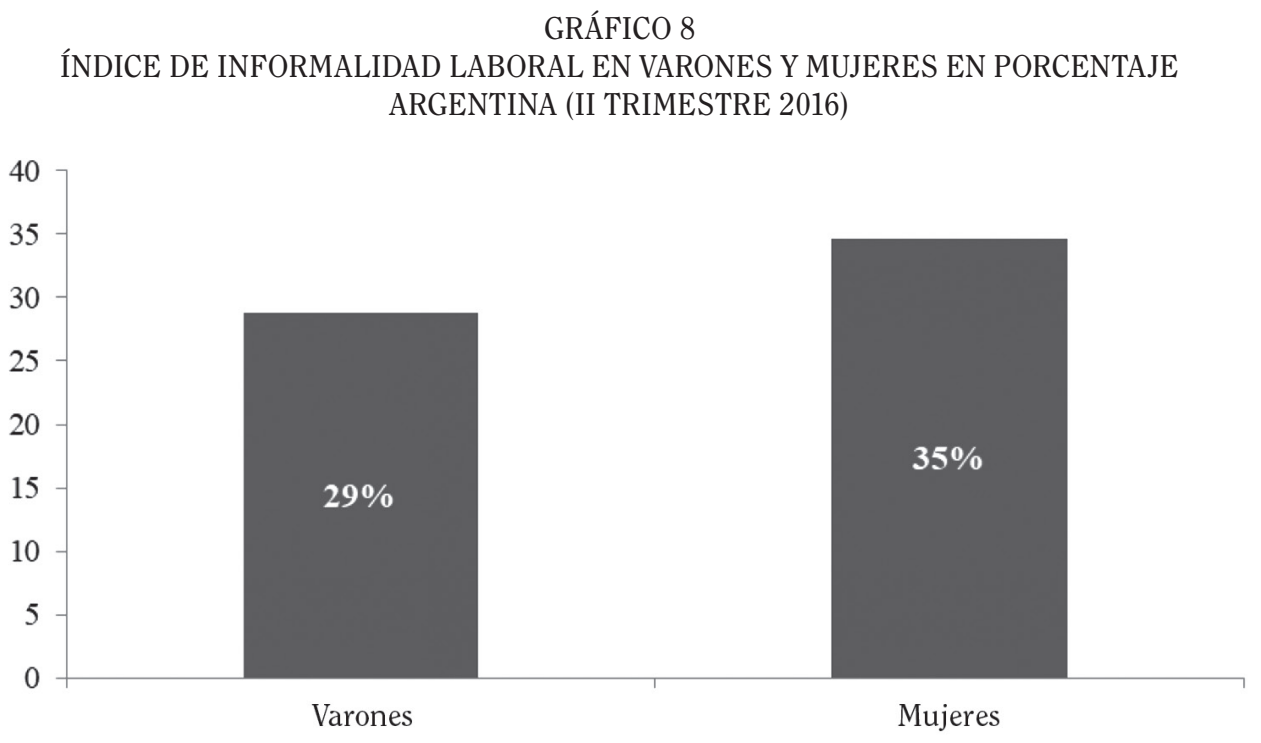

Fuente: Elaboración propia con base en EPH- INDEc, 2004 y 2016.

La informalidad laboral forma parte de los condicionantes de la desigualdad en los ingresos de varones y mujeres, esto se constata cuando se observa que la brecha salarial entre ambos se acrecienta significativamente con respecto al trabajo formal, ubicándose en $39 \%$ para el II trimestre de 2016. Durante las gestiones kirchneristas (2003-2015), si bien se redujo la brecha salarial por género en el caso de los trabajadores y trabajadoras registradas y se produjo una disminución del nivel de informalidad laboral de las mujeres (en general $y$ con respecto a los varones), la brecha salarial de género en el trabajo no registrado se mantuvo en niveles muy altos rondando el $40 \%$. Mientras que en el año 2007, la brecha se ubicó en 42\%, para el año 2015 solo se redujo dos puntos porcentuales ubicándose en $40 \%$, con oscilaciones que no bajaron del 35\%. Así, en términos de la brecha salarial por género, las mujeres no registradas son las más afectadas (tabla 8). 
TABLA 8

SALARIOS Y BRECHA SALARIAL DEL EMPLEO REGISTRADO Y NO REGISTRADO, SEGÚN SEXO EN VALORES ABSOLUTOS (PESOS) Y PORCENTAJE ARGENTINA (2007-2016)

\begin{tabular}{c|c|c|c|c|c|c}
\hline \multirow{2}{*}{ AÑO } & \multicolumn{3}{|c|}{ SALARIOS REGISTRADOS } & \multicolumn{3}{c}{ SALARIOS NO REGISTRADOS } \\
\cline { 2 - 6 } & VARÓN & MUJER & BRECHA & VARÓN & MUJER & BRECHA \\
\hline 2007 & $\$ 1588,3$ & $\$ 1274,9$ & $-20 \%$ & $\$ 1063,6$ & $\$ 614,1$ & $-42 \%$ \\
2008 & $\$ 1965,6$ & $\$ 1656,5$ & $-16 \%$ & $\$ 1393,3$ & $\$ 813,8$ & $-42 \%$ \\
2009 & $\$ 2353,7$ & $\$ 2005,1$ & $-15 \%$ & $\$ 1600,2$ & $\$ 975,1$ & $-39 \%$ \\
2010 & $\$ 2894,0$ & $\$ 2438,0$ & $-16 \%$ & $\$ 1967,0$ & $\$ 1189,0$ & $-40 \%$ \\
2011 & $\$ 3776,0$ & $\$ 3111,0$ & $-18 \%$ & $\$ 2430,0$ & $\$ 1533,0$ & $-37 \%$ \\
2012 & $\$ 4756,0$ & $\$ 3947,0$ & $-17 \%$ & $\$ 2868,0$ & $\$ 1862,0$ & $-35 \%$ \\
2013 & $\$ 5795,0$ & $\$ 4740,0$ & $-18 \%$ & $\$ 3859,0$ & $\$ 2411,0$ & $-38 \%$ \\
2014 & $\$ 7699,0$ & $\$ 6260,0$ & $-19 \%$ & $\$ 4838,0$ & $\$ 2988,0$ & $-38 \%$ \\
2015 & $\$ 10420,0$ & $\$ 7748,0$ & $-26 \%$ & $\$ 7635,0$ & $\$ 4573,0$ & $-40 \%$ \\
2016 & $\$ 13834,0$ & $\$ 11305,7$ & $-18 \%$ & $\$ 8593,8$ & $\$ 5258,8$ & $-39 \%$ \\
\hline
\end{tabular}

Fuente: $\quad$ Elaboración propia con base en EPH-INDEC, 2007-2016.

En este sentido, si se analiza el promedio de años de estudio $y$ de experiencia laboral para ambos grupos considerando la variable registro, surge que efectivamente tanto varones como mujeres no registrados tienen menos años de estudio y menor experiencia laboral en promedio. Sin embargo, si se examina la diferencia entre varones y mujeres no registradas, se verifica que al igual que el mercado laboral a nivel agregado, las mujeres tienen mayor cantidad de años de estudio, aunque menor cantidad de años de experiencia laboral. La evidencia obtenida es consistente con la existencia de factores ajenos a las características específicas de las trabajadoras en cuanto a su elegibilidad para trabajos registrados.

Con relación al estudio, las mujeres no registradas tienen en promedio 11,4 años y las mujeres registradas tienen 13,7 años. En relación a la experiencia laboral, las no registradas tienen en promedio 20,7 años y las registradas ascienden a 21,9 años. Por su parte, los varones no registrados tienen en promedio 10,8 años de estudio y los registrados poseen 12,5 años. En experiencia laboral, los registrados cuentan en promedio con 18 años y los no registrados con 22,5 años (tabla 9). 
TABLA 9

AÑOS PROMEDIO DE ESTUDIO Y DE EXPERIENCIA DE PERSONAS TRABAJADORAS

SEGÚN REGISTRACIÓN LABORAL

ARGENTINA (II TRIMESTRE 2016)

\begin{tabular}{c|cc|cc}
\hline & \multicolumn{2}{|c|}{ VARÓN } & \multicolumn{2}{c}{ MUJER } \\
\hline PROMEDIO & AÑOS DE ESTUDIO & $\begin{array}{c}\text { EXPERIENCIA } \\
\text { LABORAL }\end{array}$ & AÑOS DE ESTUDIO & $\begin{array}{c}\text { EXPERIENCIA } \\
\text { LABORAL }\end{array}$ \\
\hline $\begin{array}{c}\text { Trabajadores no } \\
\text { registrados }\end{array}$ & 10,8 & 18,02 & 11,4 & 20,7 \\
$\begin{array}{c}\text { Trabajadores } \\
\text { registrados }\end{array}$ & 12,5 & 22,5 & 13,7 & 21,9 \\
\hline
\end{tabular}

Fuente: Elaboración propia con base en EPH-INDEC, 2016.

\section{LA CAÍDA DEL PODER ADQUISITIVO EN LOS} CONVENIOS FEMINIZADOS

Una de las características de la inserción laboral femenina es la mayor participación en las profesiones asociadas al cuidado como la salud, el servicio doméstico y la educación (tabla 10).

TABLA 10

TASA DE FEMINIZACIÓN PROFESIONAL SEGÚN RAMA DE ACTIVIDAD EN PORCENTAJE ARGENTINA (II TRIMESTRE 2015)

\begin{tabular}{cc}
\hline SECTOR & TASA DE FEMINIZACIÓN \\
\hline Educación & $76 \%$ \\
Salud & $68 \%$ \\
Trabajo doméstico & $99 \%$ \\
\hline
\end{tabular}

Fuente: Elaboración propia con base en EPH, 2015.

Valeria Esquivel (2010) demostró que en Argentina -consistentemente con la evidencia internacional-, tanto la feminización como el componente de cuidado en las diversas profesiones afectan negativamente los salarios percibidos por las personas trabajadoras. Como se observa en los datos de la EPH, para el II trimestre de 2016 , un $38 \%$ de las mujeres se insertan en dichas actividades mientras que la cifra cae al $6 \%$ cuando se trata de varones (gráfico 9). 
GRÁFICO 9

ÍNDICE DE INFORMALIDAD LABORAL EN VARONES Y MUJERES EN PORCENTAJE ARGENTINA (II TRIMESTRE DE LOS AÑOS 2004-2016)

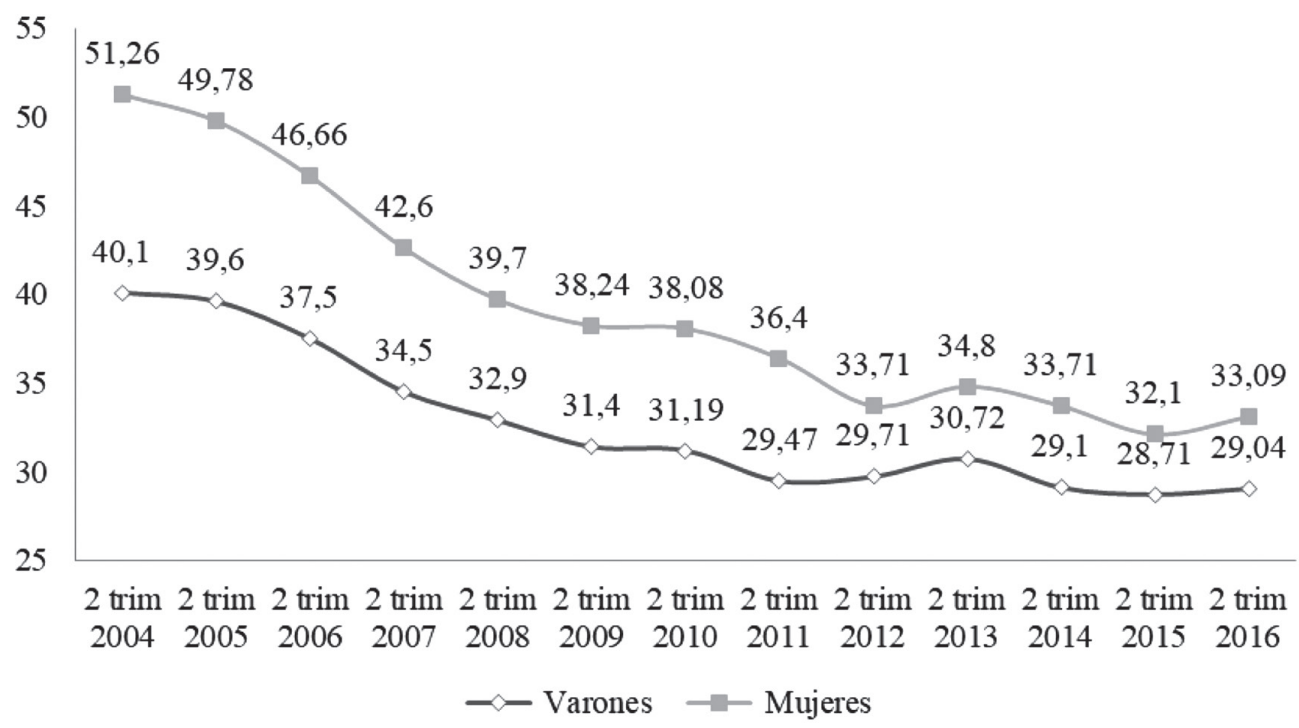

Fuente: Elaboración propia con base en EPH-INDEc, 2004-2016.

TABLA 11

VARIACIÓN DE PODER ADQUISITIVO DE CONVENIOS FEMINIZADOS CON RESPECTO AL SALARIO MEDIANO DE PERSONAS TRABAJADORAS REGISTRADAS EN PORCENTAJE ARGENTINA (2015-2017)

\begin{tabular}{c|ccc}
\hline CONVENIOS & \multicolumn{3}{c}{ VARIACIÓN DE PODER ADQUISITIVO } \\
\hline Sanidad & $2016 / 2015$ & $2017 / 2016$ & $2017 / 2015$ \\
\hline Docentes PBA & $-2,9 \%$ & $-2,8 \%$ & $-5,6 \%$ \\
Personal Doméstico & $-3,9 \%$ & $5,7 \%$ & $-9,3 \%$ \\
Personal de Maestranza & $-3,7 \%$ & $2,8 \%$ & $-14,1 \%$ \\
Salario mediano de personas trabajadoras registradas & $-0,4 \%$ & $-1,6 \%$ & $-3,3 \%$ \\
\hline
\end{tabular}

Fuente: $\quad$ Elaboración propia con base en IPC-CABA, SIPA-MTErss y datos extraídos de los convenios, 2015-2017.

En efecto, cuando se toma la variación del poder adquisitivo de los principales convenios feminizados, con respecto al salario mediano de las personas trabajadoras registradas de la economía entre 2015 y 2017, se corrobora la existencia de una penalidad que ejerce la feminización como componente del cuidado, dado que la evolución de los salarios de los trabajadores y las trabajadoras de los convenios feminizados tuvo una tendencia negativa. Si se toma la variación del poder adquisitivo de 2016 con respecto a 2015 , se observa que la mayoría 
de los convenios feminizados que componen la muestra de la tabla 11, manifestaron una pérdida de poder adquisitivo más importante que el salario mediano de personas trabajadoras registradas, siendo la excepción el personal de maestranza.

Si se toma en consideración la evolución del poder adquisitivo de 2017 con respecto a 2016, la trayectoria de los convenios feminizados es similar, evidenciando una evolución mucho más negativa que la del salario mediano de la economía. En este período, resulta particularmente pronunciada la caída del poder adquisitivo en el personal doméstico, que se ubicó en $-9,3 \%$, mientras que el salario mediano fue de $-1,6 \%$. Cabe destacar la llamativa excepción comprendida por el poder adquisitivo de las personas docentes de la Provincia de Buenos Aires (creció 5,7\%) en este período, dado que el sector estuvo caracterizado por una importante lucha salarial emprendida por el gremio. Por último, si se considera la variación de poder adquisitivo de 2017 con respecto a 2015, se observa que en los convenios feminizados la pérdida es más pronunciada que en el salario mediano de la economía y particularmente pronunciada en el personal doméstico que manifestó una caída de $-14,1 \%$ con respecto a $-3,3 \%$. Sanidad también expresa una caída de $-5,6 \%$; contrariamente, el personal docente de la PBA y el personal de maestranza muestran una evolución positiva.

\section{UN MODELO ECONOMÉTRICO PARA LAS DIFERENCIAS DE INGRESOS LABORALES}

El análisis de las remuneraciones e ingresos laborales seguido en los apartados anteriores evidencia la existencia de una brecha persistente entre varones $y$ mujeres durante todo el período considerado. La presencia de factores estructurales que determinan una inserción laboral diferencial es la hipótesis que se sostiene en este trabajo: la mayor dedicación relativa de las mujeres a las actividades de cuidado no remunerado al interior del hogar, a lo que se agrega la mayor inserción de las mujeres trabajadoras en actividades con menor remuneración relativa - como son las profesiones del cuidado-y la menor tasa de informalidad. Estos se traducen en los fenómenos de techos y paredes de cristal, así como, pisos pegajosos que terminan derivando en la brecha salarial. En definitiva, tienden a operar sobre las mujeres dos fenómenos: por un lado, la menor inserción laboral femenina que además de una menor tasa de actividad implica menos horas laborales, $y$ por otro lado, la sobrerrepresentación de las mujeres en sectores y actividades de menor paga relativa.

Si bien, el análisis descriptivo desarrollado en las secciones precedentes es consistente con la presencia de los factores descriptos, la posibilidad latente de interacciones de segundo orden o interrelaciones entre las variables operan como límite del enfoque metodológico. En este sentido, se desarrolla en esta sección un modelo econométrico para las remuneraciones donde se incluyen las variables consideradas en el análisis y una serie de controles típicos de las ecuaciones de Mincer (Heckman, Lochner y Todd, 2006): horas trabajadas, años de experiencia y años de educación. En ambos casos, se aplicó el método robusto para la estimación de las varianzas.

Como estrategia metodológica, se construyeron una serie de variables a partir de las cuales se estimó una regresión lineal considerando el logaritmo del salario o ingresos laborales $(\mathrm{EPH}$, en dos periodos segundo trimestre de 2004 y el segundo trimestre de 2016) como variable a explicar. El modelo se estimó incluyendo a todos los ocupados, no solamente a los trabajadores en relación de dependencia. Los regresores considerados incluyen variables indicadoras para el sector de inserción laboral: Industria, Construcción, Comercio, Finanzas y Servicios. Adicionalmente, se incluyó una variable indicadora de las Profesiones del Cuidado (salud, educación no universitaria y servicio doméstico). También se incluyen como regresores la presencia de menores de 6 años o menos en el hogar, una variable indicadora de empleo público, una variable indicadora de registración $y$ si el puesto es directivo o jefatura. Para captar el efecto diferencial de cada uno de los elementos considerados sobre las mujeres se incluyeron también como regresores las interacciones entre las variables $y$ una variable indicadora de género femenino (tabla 12). 
TABLA 12

MODELO DE MINCER PARA LOS INGRESOS LABORALES

ARGENTINA (II TRIMESTRE 2004 Y II TRIMESTRE 2016)

\begin{tabular}{|c|c|c|}
\hline \multirow{2}{*}{ REGRESOR } & \multicolumn{2}{|c|}{ AÑO } \\
\hline & 2004 & 2016 \\
\hline Industria & $0,16^{* * *}$ & $0,14 * * *$ \\
\hline Interacción Industria mujer & $-0,16 * * *$ & $0,25^{* * *}$ \\
\hline Construcción & 0,02 & 0,01 \\
\hline Interacción construcción mujer & 0,12 & $0,28 * * *$ \\
\hline Comercio & $0,05^{* *}$ & $0,37 * * *$ \\
\hline Interacción Comercio mujer & $-0,21^{* * *}$ & $0,11^{* *}$ \\
\hline Finanzas & $0,18^{* * *}$ & $0,26 * * *$ \\
\hline Interacción Finanzas mujer & 0,06 & $0,11^{*}$ \\
\hline Servicios & 0,00 & 0,02 \\
\hline Interacción Servicios mujer & $-0,04$ & $0,26 * * *$ \\
\hline Ocupación del cuidado & $0,09^{* * *}$ & $0,09 * * *$ \\
\hline Interacción Ocupación del cuidado mujer & $-0,25^{* * *}$ & $-0,31 * * *$ \\
\hline Menor6 & $-0,04^{* * *}$ & $-0,00$ \\
\hline Interacción Menor6 mujer & $-0,04^{* * *}$ & $-0,06^{* * *}$ \\
\hline Registrado & $0,76^{* * *}$ & $0,74^{* * *}$ \\
\hline Interacción Registrado mujer & $-0,08 * * *$ & $-0,17 * * *$ \\
\hline Publico & $0,08^{* * *}$ & $0,14^{* * *}$ \\
\hline Interacción Público mujer & $-0,02$ & $-0,00$ \\
\hline Dirección & $0,82^{* * *}$ & $0,64 * * *$ \\
\hline Interacción Dirección mujer & $-0,17$ & $-0,02$ \\
\hline Jefe & $0,32 * * *$ & $0,31 * * *$ \\
\hline Interacción Jefe mujer & $-0,07$ & $-0,00$ \\
\hline Años de educación & $0,01^{* * *}$ & $0,01^{* * *}$ \\
\hline Horas totales & $0,01^{* * *}$ & $0,02 * * *$ \\
\hline Experiencia & $0,01^{* * *}$ & $0,02 * * *$ \\
\hline Experiencia 2 & $-0,00 * * *$ & $-0,00 * * *$ \\
\hline Constante & $4,72 * * *$ & $7,5^{* * *}$ \\
\hline Tamaño de la muestra & 12899 & 12865 \\
\hline Coeficiente de determinación & 0,58 & 0,56 \\
\hline
\end{tabular}

Fuente: Elaboración propia a partir de EPH-INDEc, 2004 y 2016.

Nota: *: El coeficiente es significativo a 10\% **: El coeficiente es significativo a 5\%. ***: El coeficiente es significativo a $1 \%$. 
Las estimaciones para la rama de inserción laboral están en línea con los resultados surgidos del análisis descriptivo. En primer lugar, los sectores industria, construcción, comercio, finanzas y servicios están acompañados por coeficientes positivos. Sin embargo, cuando se analiza la interacción entre estos sectores y la variable de género resulta que el efecto de las actividades sobre las remuneraciones es diferente según se trate de un hombre o de una mujer. Una cuestión a destacar es que los coeficientes de industria y comercio, que eran negativos para las interacciones en 2004 se volvieron positivos en 2016 , lo cual indica que, dadas las mismas condiciones de años de educación, horas trabajadas y experiencia laboral, las mujeres ganan más que los varones en el sector industrial. Sin embargo, cabe destacar la baja participación femenina en ese sector. Una cuestión también relevante en función de la hipótesis que se plantea en este trabajo es el coeficiente negativo que tiene la interacción entre el sector cuidado y la variable género. Además, la suma del efecto directo (el coeficiente de cuidado) y el coeficiente de interacción (interacción cuidado y mujer) resulta negativo tanto en 2004 como en 2016. En definitiva, surge del modelo estimado que existe una penalización a las mujeres que se dedican a las profesiones del cuidado.

Respecto a la presencia de menores de 6 años en el hogar (menor6 e interacción mujer menor6), el resultado indica una penalización que opera adicionalmente en el caso de las mujeres. Esto es esperable con relación a la desigual distribución de las tareas reproductivas al interior del hogar. Es destacable que este efecto se sostiene aun cuando la variable horas trabajadas se incluye en la regresión y resulta ser significativa. En definitiva, la doble jornada laboral opera como una penalización sobre los ingresos laborales de las mujeres, que trasciende el hecho de que estas tienen menos tiempo disponible para dedicarse al trabajo productivo.

La registración tiene un efecto positivo sobre los salarios, lo cual se refleja en el coeficiente positivo y significativo que acompaña a la variable. En el caso de las trabajadoras, los beneficios de la registración son menores, ya que la interacción entre la variable y el género resulta negativa y significativa. Aunque el efecto neto es positivo, en promedio, las mujeres registradas incrementan menos su ingreso respecto de las no registradas, mientras que los varones registrados tienen mayor brecha en sus ingresos respecto de los no registrados.

Con relación a las personas trabajadoras del sector público, el efecto en relación al género no resulta significativo, manteniendo constantes todas las variables, mujeres y varones obtienen el mismo efecto por trabajar en el sector público. Hay dos posibles interpretaciones en este resultado, las cuales resultan complementarias: la primera es que las mujeres tienden a insertarse laboralmente en sectores donde los salarios públicos son superiores a los privados como educación y salud, la segunda es que tanto los salarios como las jerarquías y actividades en el sector público se encuentran mucho más regulados que los del sector privado, garantizando con más eficacia el derecho a la igualdad de género en los salarios percibidos.

Tanto las actividades con responsabilidad directiva como de jefatura (con personal a cargo) tienen un efecto positivo $y$ significativo sobre los salarios, pero no existen efectos positivos o negativos significativos con relación al género. Por último, los controles sobre los años de educación, horas trabajadas, experiencia y experiencia al cuadrado tienen los signos esperados.

\section{CONCLUSIONES}

El análisis de los datos desarrollados a lo largo del artículo permite aportar evidencia empírica en torno a dos cuestiones, por un lado, la existencia de una serie de inequidades que afectan a las mujeres en el mercado laboral de la Argentina reciente; por otro lado, la evidencia también es consistente con la hipótesis de que la serie de desigualdades observadas están relacionadas a una inserción laboral diferente entre varones y mujeres.

Analizar el perfil de inserción laboral de las mujeres implica diferenciar el trabajo productivo (el que se realiza en el mercado de manera remunerada) del trabajo reproductivo (el que se realiza al interior de los hogares sin remuneración). Son justamente las mujeres, 
quienes cargan con la mayor parte del trabajo doméstico no remunerado (3 horas diarias más que los varones) y dedican paralelamente menos tiempo a actividades productivas. La evidencia obtenida es consistente con la hipótesis de que la división sexual del trabajo posiciona a las mujeres en desventaja al momento de insertarse laboralmente. Esta división sexual del trabajo no solo opera al interior de los hogares, ya que en los trabajos asociados a tareas del cuidado y donde las mujeres se insertan de manera más intensiva, se constata la existencia de una doble penalidad en las remuneraciones; tanto por ser las ocupaciones del cuidado, trabajos peor remunerados a iguales condiciones de experiencia y años de estudio, como por el hecho de ser mujeres. Por otra parte, a pesar de haberse incorporado masivamente al mercado de trabajo, ante un contexto de caída del empleo (como el actual), las mujeres son las primeras en ser expulsadas del mercado de trabajo, tienen mayor tasa de desempleo y una menor actividad.

A la luz del análisis detallado de estas desigualdades, se puede considerar los cambios operados en las distintas gestiones de gobierno bajo análisis, contribuyendo a la construcción de una agenda que incorpore la perspectiva de género en el diseño de políticas públicas. Existe una serie de indicadores económicos que mejoraron considerablemente en las gestiones con una dinámica virtuosa del mercado de trabajo en términos de generación de empleo, crecimiento del salario real e inclusión de los sectores más vulnerables. Un claro ejemplo es la evolución de la brecha salarial de género en el trabajo registrado, que se redujo once puntos porcentuales entre 2004 y 2015; lo mismo ocurre cuando se analiza la evolución de la informalidad laboral según género durante los últimos años. La cantidad de mujeres no registradas se redujo considerablemente entre 2004 y 2007 en general, y con relación a los varones en particular. Ahora bien, cuando se considera la evolución de la brecha salarial por género en el trabajo no registrado, se observa que esta se mantuvo en niveles muy altos durante todo el periodo de crecimiento económico con incremento en materia de puestos de trabajo $y$ niveles salariales (que abarcó los años de 2004 a 2015), rondando el 40\%. Aquí, las orientaciones macroeconómicas impactan en menor escala y alertan sobre la necesidad de políticas específicas para intervenir eficazmente.

En este sentido, a partir del análisis de la dinámica del mercado de trabajo en los últimos años, es posible inferir que la persistencia de las desigualdades de género en el mercado de trabajo argentino se vincula a elementos relativamente estructurales como los que se han enumerado en este trabajo, entre los que sobresale la desigual distribución de las tareas reproductivas entre hombres $y$ mujeres, tanto al interior de los hogares como en el mercado laboral, a través de la mayor dedicación de las mujeres a profesiones de cuidado. Por lo cual, requiere la implementación de políticas públicas específicas para lograr algún impacto de hecho (en casos como la brecha salarial en el mercado informal) o erradicarlas definitivamente. El contexto macroeconómico favorable, es preciso acompañarlo de políticas sectoriales específicas.

\section{REFERENCIAS}

Arriagada, I. (1997). Realidades y mitos del trabajo femenino urbano en América Latina. Serie Mujer y Desarrollo, 21. Santiago de Chile: CEPAL.

Barrancos, D. (2007). Mujeres en la sociedad argentina. Una historia de cinco siglos. Buenos Aires: Sudamericana.

Basualdo, V. (2012). Informe anual del CELS: Avances y desafios de la clase trabajadora en la Argentina de la posconvertibilidad 2003-2010. Buenos Aires: CELS.

Beccaria L. y Maurizio, R. (2008). Mercado de trabajo y distribución personal del ingreso. En Lindenboim, Javier (comp.), Trabajo, ingresos y politicas en Argentina: contribuciones para pensar en el siglo $X X$. Buenos Aires: Eudeba.

Beccaria, L. (2007). El mercado de trabajo luego de la crisis. Avances y desafíos. En Kosacoff, Bernardo. (ed). Crisis, recuperación y nuevos dilemas: la economía argentina, 2002-2007. Buenos Aires: CEPAL. 
Beccaria, L; Maurizio, R. y Vázquez, G. (2015). Desigualdad e informalidad en América Latina: el caso de la Argentina. En Amarate, V. y Arim, R. (eds.), Desigualdad e informalidad: un análisis de cinco experiencias latinoamericanas. Santiago de Chile: CEPAL, p. 89-129.

Becker, G. (1973). A Theory of Marriage, Part I. Journal of Political Economy, 81 (4), 813-846.

Becker, G. (1974a). A Theory of Marriage, Part II. Journal of Political Economy, 82 (2), 11-26.

Becker, G. (1974b). On the Relevance of the New Economics of the Family. American Economic Review, 64 (2), 317-319.

Brizuela, R. y Tumini, L. (agosto de 2008). Inequidades de género en el mercado de trabajo de la Argentina: las brechas salariales. Revista de Trabajo, 6 .

Cerrutti, M. (2000). Economic reform, structural adjustment and female labor force participation in Buenos Aires, Argentina. World Development, 28, (5).

CIFRA-CTA (julio de 2011). El mercado de trabajo en la posconvertibilidad. Documento de trabajo. Buenos Aires, Argentina.

Contartese, D. y Maceira, V. (2006). Diagnóstico sobre la situación laboral de las mujeres. Segundo trimestre de 2005. Trabajo, ocupación y empleo, 3. Buenos Aires: SSPTYEL, MTEYSS.

Contreras, D. y Gallegos, S. (2007). Descomponiendo la desigualdad salarial en América Latina: ¿una década de cambios? Santiago de Chile: CEPAL.

D’Alessandro, M. (2016). Economía Feminísta: Como construir una sociedad igualitaria sin perder el glamour. Buenos Aires: Sudamericana.

Esquivel, V, (2012). La economía feminista desde América Latina: una hoja de ruta sobre los debates actuales en la región. Santo Domingo, República Dominicana: ONU-MUJERES.

Esquivel, V. (2009). Uso del tiempo en la Ciudad de Buenos Aires. Libros de la Universidad, 33. San Miguel: Instituto de Ciencias-UNGS.
Esquivel, V. (2010). Care workers in Argentina: At the crossroads of labour market institutions and care services. International Labour Review, 149 (4), pp. 477-493.

Esquivel, V. (2011). La Economía del Cuidado en América Latina: poniendo a los cuidados en el centro de la agend. Serie "Atando Cabos; deshaciendo nudos". Panamá: Programa de las Naciones Unidas para el Desarrollo, Centro Regional de América Latina y el Caribe, Área de Práctica de Género.

Esquivel, V. (2011b). La Economía del cuidado: un recorrido conceptual. En Norma Sanchís (comp.), Aportes al debate del Desarrollo en América Latina. Una perspectiva feminista. Buenos Aires: Red Género y Comercio.

Ferber, M. y Nelson, J. (1993). Beyond Economic Man. Chicago: The University of Chicago Press.

Gamba, S. (2007). Diccionario de estudios de género y feminismos. Buenos Aires, Argentina: Biblios.

García de Fanelli, A. (1989). Patrones de desigualdad social en la sociedad moderna: una revisión de la literatura sobre discriminación ocupacional y salarial por género. Desarrollo Económico, 29 (114), pp. 239-264.

Gardiner, J. (1997). Gender, Care and Economics. Londres, Inglaterra: MacMillan.

Heckman, J.; Lochner, L.; Todd, P. (2006). Earnings Functions, Rates of Return and Treatment Effects: The Mincer Equation and Beyond. Handbook of the Economics of Education 1 (pp. 307-458). Amsterdam, North-Holland.

Hernández García, Y. (2006). Acerca del género como categoría analítica. Revista Crítica de Ciencias Sociales y Jurídicas, 13. Santiago, Cuba: Universidad de Oriente.

Instituto Nacional de Estadísticas y Censos (INDEC) (2004). Encuesta Permanente de Hogares (EPH), segundo trimestre.

Instituto Nacional de Estadísticas y Censos (INDEC) (2016). Encuesta Permanente de Hogares (EPH), segundo trimestre. 
Instituto Nacional de Estadísticas y Censos (INDEC) (2013). Encuesta sobre Trabajo No Remunerado y del Uso del Tiempo realizada.

Kulfas, M. (2016). Los tres kirchnerismos. Una historia de la economía argentina 20032015. Buenos Aires: Siglo XxI.

Larrañaga, I.; Arregui, B. y Arpal, J. (2004). El trabajo reproductivo o doméstico. La Gaceta Sanitaria, 18, (Supl. 1). España.

Meza González, L. (enero-marzo, 2005). Mercados laborales locales y desigualdad salarial en México. El Trimestre Económico, LXXII (285).

Nelson, J. (1996). Feminism, Objectivity and Economics. Londres, Inglaterra: Routledge.

Novick, M.; Rojo, S. y Castillo, V. (comp) (2008). El trabajo femenino en la post convertibilidad. Argentina 2003-2007. Chile: CEPAL, Naciones Unidas.

Pérez Orozco, A. (enero-junio 2005). Economía del género y economía feminista, ¿conciliación o ruptura. Revista venezolana de estudios de la mujer, 10 (24). Caracas, Venezuela.

Pérez, P. (2008). Desigualdades de género en el mercado de trabajo argentino (1955-2003). Trabajos y Comunicaciones 34. Buenos Aires, Argentina: FAHCE, p. 171-200.

Picchio, A. (1999). Visibilidad analítica y política del trabajo de reproducción social. En C. Carrasco (Ed.), Mujeres y economía. Barcelona, España: Icaria-Antrazyt.

Picchio, A. (2005). La economía política y la investigación sobre las condiciones de vida. En Gemma Cairo i Céspedes y Maribel Mayordomo Rico (comps),
Por una economía sobre la vida. Aportaciones desde un enfoque feminista. Barcelona, España: Icaria.

Recio Cáceres, C. y Torns, T. (2012). Las desigualdades de género en el mercado de trabajo: entre la continuidad y las transformaciones. Barcelona, España: Universitat Autónoma de Barcelona.

Rodríguez Enríquez, C. (2010). Análisis económico para la equidad: los aportes de la economía feminista. Saberes. Revista de Ciencias Económicas y Estadística, 2.

Rodriguez Enríquez, C. (marzo-abril 2015). Economía feminista y economía del cuidado. Aportes conceptuales para el estudio de la desigualdad. Nueva Sociedad, 256.

Santarcángelo, J. E. (2011). Distribución del ingreso y desarrollo económico. Lecciones del caso argentino. Revista de Ciencias Sociales, 21. Argentina: Universidad Nacional de Quilmes.

Sarrió, M., Barberá, E., Ramos, A. y Candela, C. (2002). Glass ceiling in the professional promotion of women. Revista de Psicología Social, 17 (2), pp.167-182.

Sen, A. (1990). Gender and Cooperative Conflicts. En I. Tinker (Ed.), Persistent Inequalities (pp. 123-149). New York: Oxford University Press.

Simón, H. (septiembre 2009). La desigualdad salarial en España: una perspectiva internacional y temporal. Investigaciones Económicas, xxxıII. Madrid, España: Fundación SEPI.

Fecha de ingreso: 07/12/2017 Fecha de aprobación: 08/07/2019 
